\title{
3D Printed Human Auricular Model for Tissue Engineering
}

\author{
Evren Homan Gökçe ${ }^{1}$, Armağan Yalgın², Damla Ece Tapınç ${ }^{3}$, Fadime Aydın ${ }^{4}$ \\ ${ }^{1,4}$ Faculty of Pharmacy, Ege University \\ Bornova, Izmir, Turkey \\ evren.homan.gokce@ege.edu.tr; fadime.aydin@ege.edu.tr \\ ${ }^{2,3}$ Institue of Health Sciences \\ armaganyalgin@hotmail.com; damla1912@gmail.com
}

\section{Extended Abstract}

Additive manufacturing, with modern name 3D Printing processes make three-dimensional parts directly from CAD models by adding materials layer by layer. This technology offers the beneficial ability to build parts with geometric and material complexities that could not be produced by subtractive manufacturing processes. [1] Tissue engineering is an interdisciplinary field which applies the principles of engineering and the life sciences toward the development of biological substitutes that restore, maintain, or improve tissue function with cell culture techniques. [2] Tissue engineering has been the development of 3D scaffolds that guide cells to form functional tissue. Recently, mouldless manufacturing techniques known as additive manufacturing or 3D printing have been successfully used to fabricate complex scaffolds constructions. [3] These scaffolds are designed to mimic the extracellular matrix (ECM) by providing structural support as well as promoting attachment, proliferation, and differentiation with the ultimate goal of yielding functional tissues or organs. Initial attempts at developing scaffolds were problematic and subsequently inspired a growing interest in 3D printing as a mode for generating scaffolds. Utilizing three-dimensional printing (3DP) technologies, ECM-like scaffolds can be produced with a high degree of complexity and precision.[4]

The aim of this study was to use a commercial 3D printer and filaments and combine them tissue engineering techniques together for developing human auricular models. Polylactic asid (PLA), Polyvinyl alcohol (PVA), Medical grade silicone polymer filaments were printed from Ultimaker-2 3D printer. Models were sterilized and cultured with 3T3dermal fibroblasts. 3D printed models served as scaffolds for cells. Co-enyzme Q10 solid lipid nanoparticles were prepared and added in the environment of cell culture process. The effect of polymers on proliferation and presence of nanoparticles were investigated.

\section{References}

[1] N. Guo, M.C. Leu, "Additive manufacturing: technology, applications and research needs," Front. Mech. Eng., vol. 8, no. 215, 2013.

[2] J. P. Vacanti and R. Langer, "Tissue engineering: the design and fabrication of living replacement devices for surgical reconstruction and transplantation," The Lancet, vol. 35, S32-S34, 1999.

[3] D. W. Hutmacher, M. Sittinger, M. V. Risbud, "Scaffold-based tissue engineering: rationale for computer-aided design and solid free-form fabrication systems," Trends in Biotechnology, vol. 22, no. 7, pp. 354-362, 2004.

[4] A. Do, B. Khorsand, S. M. Geary, A. K. Salem, "3D Printing of Scaffolds for Tissue Regeneration Applications," Adv Healthc Mater., pp. 1742-1762, 2015. 